\title{
The Effect of Combined Treatment of Opioids With Methylphenidate on Nociception in Rats and Pain in Human
}

\author{
A. YAMAMOTOVÁ ${ }^{1}$, J. FRICOVÁ $^{2}$, R. ROKYTA ${ }^{1}$, R. ŠLAMBEROVÁ ${ }^{1}$ \\ ${ }^{1}$ Department of Normal, Pathological and Clinical Physiology, Third Faculty of Medicine, Charles \\ University, Prague, Czech Republic, ${ }^{2}$ Charles University and General University Hospital, Prague, \\ Czech Republic
}

Received March 27, 2016

Accepted October 26, 2016

\begin{abstract}
Summary
Methylphenidate hydrochloride (MPH/Ritalin) is a stimulant used for off-label management of cancer-related fatigue and sedation; however, its use in pain treatment is still relatively rare. This study 1) compares the antinociceptive effect of MPH and its combination with morphine (MOR) in adult male Wistar rats after a single administration of MPH, MOR or their combination, and 2) compares the analgesic effects of opioids and Ritalin combined therapy with opioid monotherapy in patients with cancer pain. To objectively assess physical activity during a three-week monitoring period, patients were equipped with Actiwatch Score Actigraph. Patients performed daily evaluations of pain intensity and frequency, and the extent to which pain interfered with their daily life. Our research with rats supports the evidence that MPH in lower doses has the ability to enhance the analgesic properties of morphine when the two drugs are used in combination. Results from the patient arm of our study found that short-term treatment had no significant effect on intensity or frequency of pain, however it decreased the overall burden of pain; the combined treatment of opioid and Ritalin also showed anti-sedation effects and resulted in mild improvement in one of our patient's quality of life.
\end{abstract}

\section{Key words}

Methylphenidate - Morphine • Nociception • Cancer pain • Translation research

\section{Corresponding author}

A. Yamamotová, Department of Normal, Pathological and Clinical Physiology, Third Faculty of Medicine, Charles University, Ke Karlovu 4, 12000 Prague 2, Czech Republic. E-mail: yamamoto@lf3.cuni.cz

\section{Introduction}

Most patients diagnosed with cancer suffer from pain in the terminal stages. In some cases, cancer pain is difficult to treat. Therefore, one of the main goals of this study was to find new treatments for patients with cancer pain.

Cancer is often a terminal disease. Therapy for many patients consists of palliative care with the goal of improving the quality of life. Common symptoms in cancer patients include pain, somnolence, depression, and cognitive dysfunction (Rozans et al. 2002). In some cases, commonly used analgesic strategies fail to provide sufficient pain relief and/or are accompanied by unacceptable side effects. Therefore, finding new pain treatment strategies and to study a better understanding of the mechanisms of cancer pain relief represent urgent concerns.

Psychostimulant drugs are potential candidates for adjuvant analgesic drugs. Psychostimulants have been described to induce analgesia and anti-nociception in animal models of both acute (tail-flick test, hot-plate test) (Drago et al. 1984, Lin et al. 1989) and tonic (formalin test) (Altier and Stewart 1993, Morgan and Franklin 1990) pain. Other studies have shown potentiation of opioid analgesia using psychostimulants (Dalal and Melzack 1998, Sprague and Takermori 1978). Furthermore, psychostimulants have been shown to reduce sedation and improve cognitive functions, which facilitate the use of higher doses of opioids (Dalal and Melzack 1998).

Clinical experience suggests that a combination 
treatment using opioids and psychostimulants have two advantages: 1) the combined treatment increases the analgesic effect and 2) reduces the incidence of adverse effects, because the combination allows the use of reduced doses of both analgesics. The combination is primarily used to mitigate the occurrence of somnolence and sedation induced by higher doses of opioids and to mitigate the negative effects of opioid treatment on cognitive function. Based on reduced sedation, the use of amphetamine derivatives enables the use of higher doses of opioids, especially in the terminal stages of cancer, which can add comfort to the end of life of the patients by reducing pain or at least making it more tolerable (Dalal and Melzack 1998). Therefore, the combination of opioids with psychostimulants seems to be a feasible way to improve the quality of life of patients with end stage cancer (Rozans et al. 2002).

Our previous research showed that psychostimulant drugs have analgesic effects in an animal (rat) model of nociceptive sensitivity, using the plantar test (Yamamotová et al. 2012). The results were in agreement with other experimental and clinical studies that demonstrated the analgesic effects of psychostimulants alone, as well as psychostimulants in combination with opioid analgesics (Dalal and Melzack 1998, Halladay et al. 2009, Schreiber et al. 2015).

Since psychostimulants are illicit drugs, the best candidate for use in clinical practice is methylphenidate (Ritalin), which has been used in clinical practice for treatment of children with ADHD syndrome (Attention deficit hyperactivity disorder) worldwide for almost 50 years (Challman and Lipsky 2000, Jensen 2009). Ritalin has also been used in the treatment of narcolepsy (Trenque et al. 2014), the treatment of major depressive disorder in terminally ill cancer patients ( $\mathrm{Ng}$ et al. 2014), as augmentation therapy after failure of adjunctive neuromodulation for patients with treatment-refractory bipolar depression (Adida and Azorin 2014), and in the treatment of fatigue associated with cancer chemotherapy (Lower et al. 2009). However, its use for pain treatment is still relatively rare.

The aim of our study was to link the findings of experimental studies in animal models to clinical practice in oncology, which, for various reasons, involve treatment failure of opioid analgesic medication. The analgesic effects of combined therapy of opioids and methylphenidate hydrochloride (MPH/Ritalin) will be examined and compared with opioid monotherapy. In the clinical part of the study, the subjective as well as the objective analgesic effect of combined treatments was analyzed.

\section{Methods}

Animal study

In the present study, we selected three MPH doses. The first and second doses were $0.25 \mathrm{mg} / \mathrm{kg}$ and $1 \mathrm{mg} / \mathrm{kg}$, which do not exhibit an effect in locomotor activity. The third dose was $5 \mathrm{mg} / \mathrm{kg}$, which increases motor activity but not stereotyped behavior (Gaytan et al. 1997).

Nociception was tested in three-month-old male Wistar rats $(\mathrm{N}=85)$. Latencies of forelimbs, hind limbs, and tail withdrawal reflexes to thermal nociceptive stimuli (Plantar Test, Ugo Basile, Comero, Italy) were repeatedly measured at 15-min intervals after a subcutaneous (sc) injection of $0.25 \mathrm{mg} / \mathrm{kg}, 1 \mathrm{mg} / \mathrm{kg}$, and $5 \mathrm{mg} / \mathrm{kg}$ of $\mathrm{MPH}, \mathrm{MOR}$, and their combination (MPH+MOR) in equal doses. The last measurement was performed $45 \mathrm{~min}$ after $\operatorname{drug}(\mathrm{s})$ administration. Antinociceptive effects, expressed as the Percentage Maximum Possible Effect (\%MPE), were calculated as the percentage difference between the measured response and the baseline response, divided by the difference between the maximum response (cut-off time $=22 \mathrm{~s}$ ) and the baseline response. \%MPE was calculated separately from the latencies of the tail-flick responses and paw withdrawal reflexes to thermal stimuli during the $45^{\text {th }}$ minute after drug injection.

In the plantar test, animals were freely moving in a plexiglas box (size $27 \times 17 \times 14 \mathrm{~cm}$ ) without any restriction. Nociception was tested after five-minutes of adaptation, i.e. after the disappearance of exploratory activity induced by the new environment. Forepaws were tested first, followed by hind paws, and the tail. Four repeated measurements at different locations on the distal part of the tail were used. Stimulation was repeated at approximately half-minute intervals. Mean values from the limbs and the tail were used for analysis.

All experiments were approved by the Committee for Animal Care and Use, Third Faculty of Medicine, Charles University, Prague and conducted according to the guidelines of the Ethics Committee of the International Association for the Study of Pain (Zimmermann 1983).

Human study

Two patients participated in the clinical part of 
the study. The first patient was a 63-year-old man with a 12-year history of an orofacial tumor in the retromolar area with metastases. Pain in this patient was sharp and burning with an intensity of 8-10 on a numeric rating scale (NRS). The pain was located in the neck and spread to the head and base of the tongue. Breakthrough pain occurred 2-3 times per day, with an intensity of 10 (NRS). Before entering the study, the patient was treated with transdermal fentanyl $(100 \mu \mathrm{g} / \mathrm{h})$.

The second patient was a 67 -year-old man with prostate cancer and metastases into the pelvic bones and the L2-L5 vertebrae with a strong neuropathic component in both thighs. Pain intensity was 5-7 on NRS. The patient was taking OxyContin (oxycodone) 60-80 mg/day + gabapentin $900 \mathrm{mg} /$ day.

Although pain is not considered a primary indication for methylphenidate, the potential for analgesic effects may influence the decision to use it in combination with opioids (Dalal and Melzack 1998). In cancer patients, methylphenidate can reduce opioidinduced somnolence, improve cognition, treat depression, and alleviate fatigue. Treatment is typically begun at $2.5-5 \mathrm{mg}$ in the morning and again at midday, if necessary, to keep the patient alert during the day and not interfere with sleep at night (Rozans et al. 2001).

During the first week of monitoring, patients continued on their previous medication(s). During the second week, $10 \mathrm{mg} /$ day of Ritalin was added to the treatment regimen. During the third (last) week, Ritalin therapy was discontinued.

Actigraphy was used to provide an objective estimate of physical activity and sleep. All participants were instructed to wear the Actiwatch Score (CalmNtech, UK) $24 \mathrm{~h}$ per day during the whole ( 3 week) observation period. An Actigraph is a movement detector, designed to measure ambulatory activity. The instrument is the size of a wristwatch and was worn on the non-dominant arm. Activity counts were recorded at 2-min intervals (sampling frequency).

At 5 P.M. the patients were alerted by a 'beep' to enter the required information about their current pain status - i.e. pain intensity and frequency and the extent to which pain had interfered with their daily life (dela Cruz et al. 2014). All items were assessed using a 10 point Likert's scale.

The intensity of 'current pain' was assessed using a numeric rating scale (from 0 to 9 where 9 represents maximum possible pain), the frequency and burden of pain (from 0 to 9 where 9 represents 'all-day pain' and burden).

Data from the Actigraph were analyzed using the Sleep Activity 7 program (CalmNtech). In addition to the average daytime activity, the quality of sleep was also assessed based on the duration of immobility during sleep.

This study was carried out in accordance with the Declaration of Helsinki (Br Med J 2: 177-178, 1964, as revised in 2008). After all procedures had been fully explained, each participant signed an informed consent. The study was approved by the Ethics Committee of the Third Faculty of Medicine, Charles University, Prague.

\section{Statistical analyses}

Animal study

Changes in nociception after drug administration using \%MPE were analyzed using the two-way ANOVA (between subject variability - factors drug and dose) separately for each tested body site. Where indicated, simple planned comparisons or the Bonferroni test were used in post-hoc analyses.

\section{Human study}

Descriptive statistics were used to characterize the sample. Means and standard deviations were reported for continuous variables obtained from each week of the study. Statistical differences between variables during the three-week observation periods were tested separately for each patient using the nonparametric Kruskal-Wallis test and the Mann-Whitney U test.

\section{Results}

\section{Animal study}

Effect of drugs and doses

Results are summarized in the Figures 1 and 2. The lowest dose of all drugs $(0.25 \mathrm{mg} / \mathrm{kg})$ was without any anti-nociceptive effects and withdrawal latencies were the same at all stimulated body sites (drug $\mathrm{x}$ site interaction $\mathrm{F}(4,42)=0.12, \mathrm{p}=0.98)$.

At a dose of $1 \mathrm{mg} / \mathrm{kg}$, the strongest anti-nociceptive effect was found for a combination of $\mathrm{MPH}+\operatorname{MOR}(\mathrm{F}(2,20)=6.32, \mathrm{p}=0.007)$, irrespective of the tested body site (drug $\mathrm{x}$ site interaction $\mathrm{F}(4,40)=1.03$, $\mathrm{p}=0.40$ ). 


\section{$\mathbb{B} \mathrm{FL} \mathbf{B L}$}

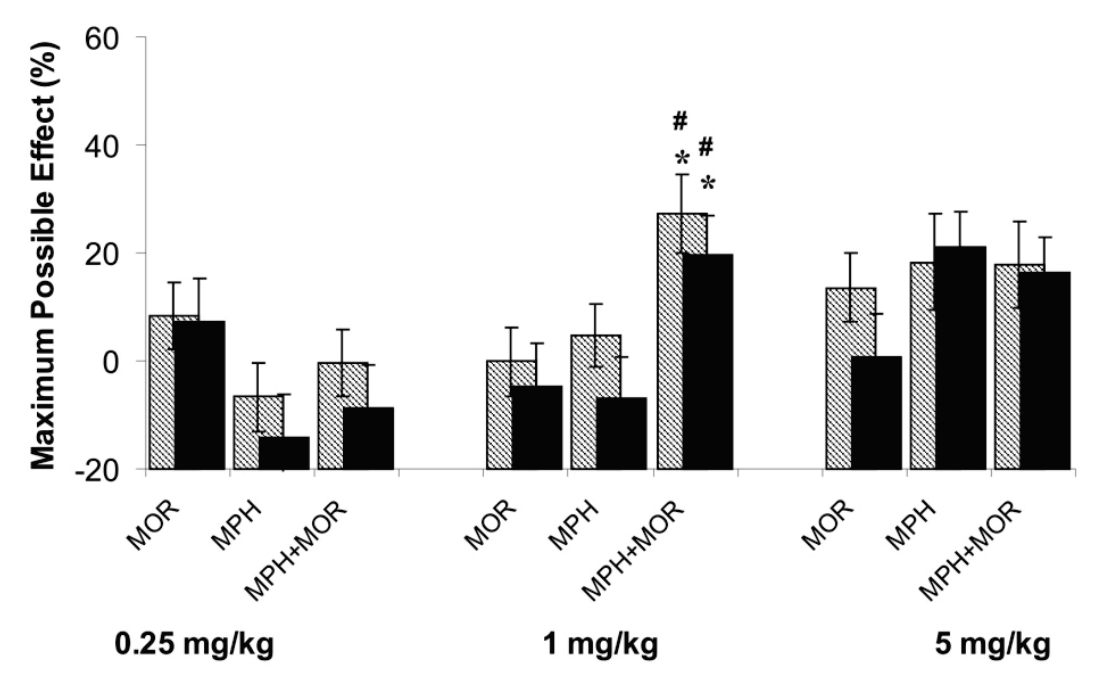

Fig. 1. Differences in analgesia on the forelimbs and hind limbs after sc administration of morphine, $\mathrm{MPH}$, or a combination. At a dose of $1 \mathrm{mg} / \mathrm{kg}$, the strongest anti-nociceptive effect was found for a combination of MPH + MOR. \# $p<0.05$ $\mathrm{MPH}+\mathrm{MOR}$ vs. MOR, $* \mathrm{p}<0.05 \mathrm{MPH}+\mathrm{MOR}$ vs. MPH.
Tail-flick

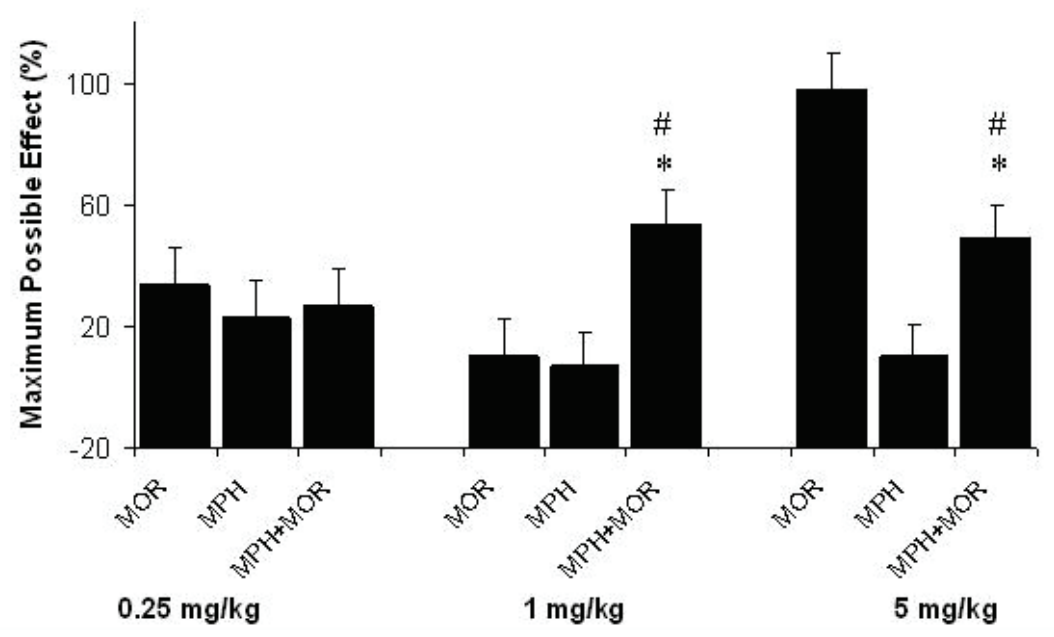

$\mathbb{\$}$ baseline $\square$ Ritalin $\square$ after

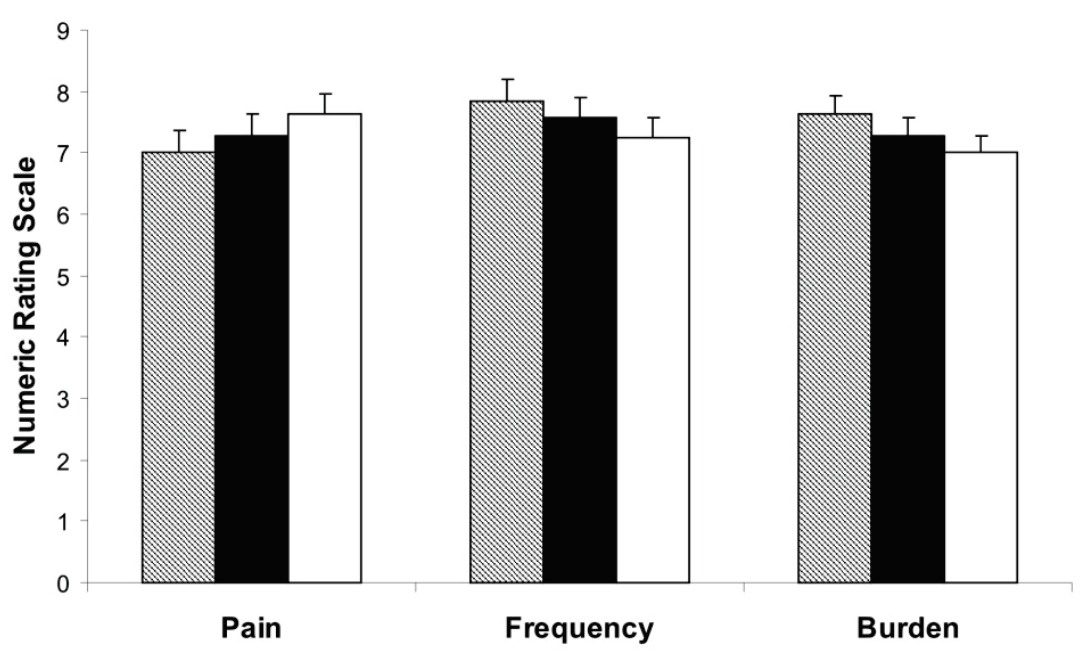

Fig. 2. Differences in analgesia on the tail after sc injection of morphine, $\mathrm{MPH}$, or a combination. At a dose of $1 \mathrm{mg} / \mathrm{kg}, \mathrm{MPH}$ increased the anti-nociceptive potency of MOR, however, at a dose of $5 \mathrm{mg} / \mathrm{kg}$ it decreased the anti-nociceptive potency of MOR. \# $p<0.05 \mathrm{MPH}+\mathrm{MOR}$ vs. MOR, $* \mathrm{p}<0.05 \mathrm{MPH}+\mathrm{MOR}$ vs. MPH.
Fig. 3. Mean (+ SEM) changes in pain intensity, frequency of pain, and interference of pain with daily life in patient No. 1 during the three-week observation period (before treatment with Ritalin, during treatment, and after discontinuation of Ritalin). No significant differences were found in any observed endpoints. 

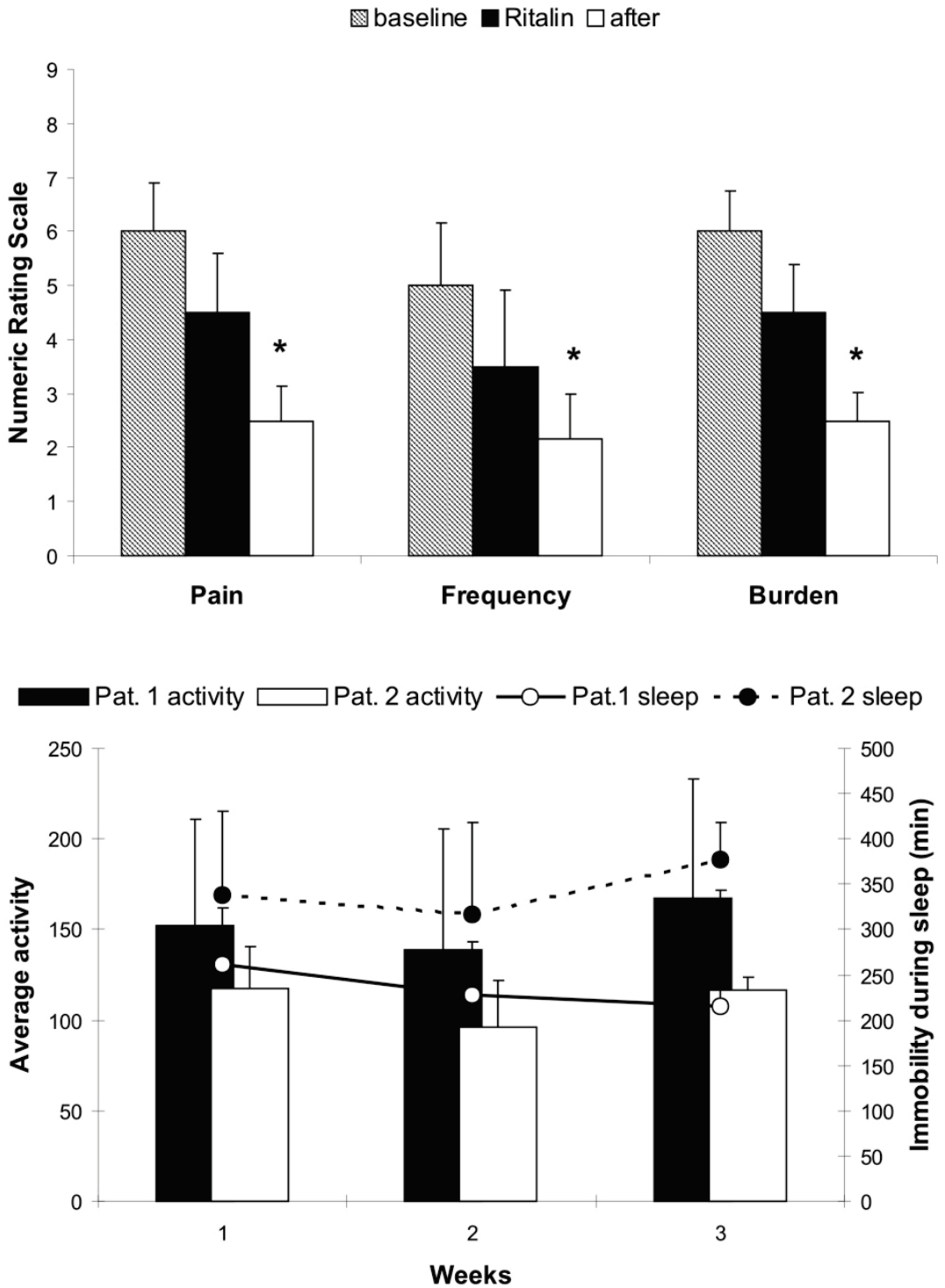

Fig. 4. Mean (+ SEM) changes in pain intensity, frequency of pain, and interference of pain with daily life in patient No. 2 during the three-week observation period (before treatment with Ritalin, during treatment, and after discontinuation of Ritalin). All pain characteristics decreased over the threeweek observation period but significant differences were only found between the baseline period and the week after Ritalin discontinuation. $* \mathrm{p}<0.05$ baseline vs. after.

Fig. 5. Average daily activity and the number of minutes of immobility during sleep ( $\pm \mathrm{SE}$ ) in two patients during a three-week observation period. Ritalin was added to each patient's pain treatment regimen during the second week (i.e. days 8-14). No significant changes in daily physical activity and immobility during sleep were found throughout the observation period.
At a dose of $5 \mathrm{mg} / \mathrm{kg}$, there were no significant differences between drugs $(F(2,14)=3.13, p=0.075)$, the effect of MOR was similar to the effect of the combination MPH + MOR; however, the effect was strongly dependent on the stimulated body site. The maximal anti-nociceptive reaction was observed on the tail (drug $x$ site interaction $\mathrm{F}(4,28)=13.77, \mathrm{p}<0.00001$ ), where MOR was more effective than MOR $+\mathrm{MPH}$ (Fig. 2).

\section{Human study}

Pain

In patient No. 1, we found no differences in either self-reported pain intensity $(\mathrm{H}=1.57, \mathrm{p}=0.46)$, pain frequency $(\mathrm{H}=1.08, \mathrm{p}=0.58)$, or overall pain burden $(\mathrm{H}=3.33, \mathrm{p}=0.19)$. However, the variable "interference of pain with daily life" showed a decreasing tendency when the first week of the study was compared with the third week $(\mathrm{p}=0.06)$ (Fig. 3).

In patient No. 2, the mean pain intensity decreased over the three-week observation period $(\mathrm{H}=8.13, \mathrm{p}=0.02)$ as did the daily frequency of pain $(\mathrm{H}=8.18, \mathrm{p}=0.02)$. Changes in the variable "interference of pain with daily life" approached, but did not achieve significance $(\mathrm{H}=5.37, \mathrm{p}=0.07)$.

In all variables, significant differences were found between the baseline period and the week after Ritalin discontinuation (pain intensity: $p=0.02$, frequency of pain: $p=0.01$, burden of pain: $p=0.03$ ) (Fig. 4).

\section{Activity and sleep}

In patient No. 1, treatment with MPH, in the form of Ritalin, did not affect average daily activity or quality of sleep, as estimated from the number of minutes of immobility $(\mathrm{H}=0.86, \mathrm{p}=0.65, \mathrm{H}=0.32, \mathrm{p}=0.85)$, respectively. In patient No. 2 , also no differences were 
found in average daily activity $(\mathrm{H}=2.59, \mathrm{p}=0.27)$ or the number of minutes of immobility during sleep $(\mathrm{H}=1.81$, $\mathrm{p}=0.40)$ (Fig. 5).

\section{Discussion}

Animal study

We found that MPH at a dose of $1 \mathrm{mg} / \mathrm{kg}$ had the ability to enhance the analgesic properties of morphine when the two drugs were used in combination. Both drugs operate in the same brain structures. Analgesic and reward effects are mediated by dopaminergic neurons, which are located in the ventral tegmental area (VTA) and project into various areas of the forebrain, including the nucleus accumbens (Altier and Stewart 1999). Opioids cause the release of dopamine from these neurons indirectly through inhibition of GABAergic neurons (Johnson and North 1992, Koob 1992), whereas psychostimulants increase extracellular dopamine directly.

The therapeutic effects of MPH are thought to be mediated by an increase in the synaptic concentration of dopamine and noradrenaline, particularly in the striatal and frontal regions (Volkow et al. 2002), which is induced by blocking dopamine and noradrenalin transporters, respectively, the main action being on dopamine transporters.

To understand the analgesic effects of psychostimulants it is important to mention the fact that the VTA neurons process nociceptive information and participate in the modulation of pain (Moradi et al. 2014, Altier and Stewart 1999, Morgan and Franklin 1990). Activation of the dopaminergic mesolimbic reward circuit, which originates in the VTA, is postulated to preferentially suppress emotional responses to noxious stimuli (Schifirnet et al. 2014). Suppression of the nociceptive component of pain can also be affected by the descending pain modulating system, in which serotonergic and noradrenergic neurons play pivotal roles. Recent electrophysiological studies have shown that noradrenergic locus coeruleus neuronal activity and serotonergic dorsal raphe neuronal activity are both modulated by MPH (Tang and Dafny 2012, Tang and Dafny 2013). The anti-nociceptive effect of MPH has also been described in adults with ADHD; after a 3-day wash-out period, MPH administration resulted in increased pain thresholds and tolerance on the cold pressor test (Treister et al. 2013).
Human study

The pain suppressing effect of Ritalin in combination with opioids was different in our two patients. In the patient with a long history of illness and strong orofacial pain, Ritalin appeared to be completely ineffective; however, in the patient with prostate cancer and milder pain, there appeared to be some treatment benefit. This patient was also treated with gabapentin.

According to our knowledge, information about interaction between gabapentin and methylphenidate are not documented in medical literature. Just one case report was published about combined treatment of gabapentin (200 mg/day) and methylphenidate (30 mg/day) in a preadolescent with ADHD and co-morbid bipolar disorder. Both family and clinician noted improvement and stabilization of mood symptoms (Hamrin and Bailey 2001). We cannot exclude that mild treatment benefit can result from mood improvement in this patient.

Pain intensity, daily frequency of pain, and interference of pain with daily activities remained reduced even one week after Ritalin discontinuation. Vigano et al. (1995) published a similar finding for MPH in the management of psychological distress and associated somatization in a patient with terminal prostate cancer. The question arises, whether different types of pain and specific somatic locations might be more responsive to this type of therapy. Similar results were obtained in our animal model when we compared the anti-nociceptive effects on the tail and paws.

A human PET study showed that therapeutic doses of MPH block more than $50 \%$ of the dopamine transporters and significantly enhance extracellular dopamine in the brain, an effect that appears to be modulated by the rate of dopamine release (Volkow et al. 2002). It is possible that chronic pain induces disruption in dopamine signaling similar to long-term exposure to opioids (Taylor et al. 2016).

The clinical effect of MPH in humans might be influenced by several factors which follow from the study of Volkow and Swanson (2003). These factors include: dose, which is necessary to induce a dopamine increase that is perceived as reinforcing and capable of producing therapeutic effects; pharmacokinetics, i.e. the reinforcing effect of MPH is associated with rapid changes in serum concentrations and rapid dopamine increases, whereas the therapeutic effects are associated with slowly increasing serum concentrations; individual differences in $\mathrm{MPH}$ sensitivity; and context, i.e. the effects of MPH can be modulated by different situations and expectations. 
We found no significant changes in daily physical activity profiles or circadian activity rhythms (not shown, will be published separately) after Ritalin treatment, although MPH has been shown to alter circadian clocks in mice (Antle et al. 2012). Also, the number of minutes of immobility during sleep was, in our patients, similar during the entire observation period. This is in agreement with the effect of $\mathrm{MPH}$ treatment for adult ADHD, which showed no significant differences in mean Actigraph sleep parameters measured during the week-long pre-treatment and during the treatment period (Snitselaar et al. 2013); this effect was contrary to that seen in ADHD children where MPH negatively affected total sleep and reduce mean activity (De Crescendo et al. 2014).

Although we did not observe any treatment side effects in our patients, the number of spontaneous reports of adverse effects occurring during off-label use of methylphenidate after long-term treatment has been increasing over the past several years (Trenque et al. 2014). The absence of serious adverse events relative to the presence of other, rather minor, adverse events (vertigo, anxiety, anorexia, and nausea), demonstrates the tolerability and safety of MPH in cancer patients (Escalante et al. 2014).

Both patients in our study experienced improved resistance to fatigue and expressed a desired to continue methylphenidate after the study was concluded; however, a meta-analysis of methylphenidate on cancer related fatigue has provided limited evidence to support the use of methylphenidate as fatigue treatment (Gong et al. 2014).

Several limitations of this study should be mentioned. First, since it was a pilot study, we had a small number of patients. Because the patients were in the terminal stages of their diseases, we did not use a placebo control group, therefore we cannot exclude that our results were partially influenced by MPH and/or placebo. The size of placebo effect is always dependent on the expectations of the patient; however, we did not assess this factor in our study.

We did not observe any obvious analgesic effects from the combined treatment of Ritalin with opioids; however, we did observe anti-sedative effects and mild improvement in patient quality of life.

\section{Conflict of Interest}

There is no conflict of interest.

\section{Acknowledgements}

This study was supported by grant IGA NT/14484 and Prvouk P34.

\section{References}

ADIDA M, AZORIN JM: Effectiveness of methylphenidate as augmentation therapy after failure of adjunctive neuromodulation for patients with treatment-refractory bipolar depression: a case report. Neuropsychiatr Dis Treat 10: 559-562, 2014.

ALTIER N, STEWART J: The role of dopamine in the nucleus accumbens in analgesia. Life Sci 65: 2269-2287, 1999.

ANTLE MC, VAN DIEPEN HC, DEBOER T, PEDRAM P, PEREIRA RR, MEIJER JH: Methylphenidate modifies the motion of the circadian clock. Neuropsychopharmacology 37: 2446-2455, 2012.

BERRIDGE CW, DEVILBISS DM, ANDRZEJEWSKI ME, ARNSTEN AF, KELLEY AE, SCHMEICHEL B, HAMILTON C, SPENCER RC: Methylphenidate preferentially increases catecholamine neurotransmission within the prefrontal cortex at low doses that enhance cognitive function. Biol Psychiatry 60: 1111-1120, 2006.

BRUERA E, BRENNEIS C, PATERSON AH, MACDONALD RN: Use of methylphenidate as an adjuvant to narcotic analgesics in patients with advanced cancer. J Pain Symptom Manage 4: 3-6, 1989.

BRUERA E, FAINSINGER R, MACEACHERN T, HANSON J: The use of methylphenidate in patients with incident cancer pain receiving regular opiates. A preliminary report. Pain 50: 75-77, 1992.

CHALLMAN TD, LIPSKY JJ: Methylphenidate: its pharmacology and uses. Mayo Clin Proc 75: 711-721, 2000.

DALAL S, MELZACK R: Potentiation of opioid analgesia by psychostimulant drugs: a review. J Pain Symptom Manage 16: 245-253, 1998.

DE CRESCENDO F, ARMANDO F, MAZZONE L, CILIBERTO M, SCIANNAMEA M, CAROLINE FIGUEROA C, JANIRI L, QUESTED D, VICARI S: The use of actigraphy in the monitoring of methylphenidate versus placebo in ADHD: a meta-analysis. Atten Def Hyp Disord 6: 49-58, 2014. 
DELA CRUZ AM, BERNSTEIN IH, GREER TL, WALKER R, RETHORST CD, GRANNEMANN B, CARMODY T, TRIVEDI MH: Self-rated measure of pain frequency, intensity, and burden: psychometric properties of a new instrument for the assessment of pain. J Psychiatr Res 59: 155-160, 2014.

DRAGO F, CACCAMO G, CONTINELLA G, SCAPAGNINI U: Amphetamine-induced analgesia does not involve brain opioids. Eur J Pharmacol 101: 267-269, 1984.

ESCALANTE CP, MEYERS C, REUBEN JM, WANG X, QIAO W, MANZULLO E, ALVAREZ RH, MORROW PK, GONZALEZ-ANGULO AM, WANG XS, MENDOZA T, LIU W, HOLMES H, HWANG J, PISTERS K, OVERMAN M, CLEELAND C: A randomized, double-blind, 2-period, placebo-controlled crossover trial of a sustained-release methylphenidate in the treatment of fatigue in cancer patients. Cancer J 20: 8-14, 2014.

GAYTAN O, GHELANI D, MARTIN S, SWANN A, DAFNY N: Methylphenidate: diurnal effects on locomotor and stereotypic behavior in the rat. Brain Res 777: 1-12, 1997.

GONG S, SHENG P, JIN H, HE H, QI E, CHEN W, DONG Y, HOU L: Effect of methylphenidate in patients with cancer-related fatigue: a systematic review and meta-analysis. PLoS One 9: e84391, 2014.

HALLADAY LR, IÑIGUEZ SD, FURQAN F, PREVITE MC, CHISUM AM, CRAWFORD CA: Methylphenidate potentiates morphine-induced antinociception, hyperthermia, and locomotor activity in young adult rats. Pharmacol Biochem Behav 92: 190-196, 2009.

HAMRIN V, BAILEY K: Gabapentin and methylphenidate treatment of a preadolescent with attention deficit hyperactivity disorder and bipolar disorder. J Child Adolesc Psychopharmacol 11: 301-309, 2001.

JENSEN PS: Review: methylphenidate and psychosocial treatments either alone or in combination reduce ADHD symptoms. Evid Based Ment Health 12: 18, 2009.

JOHNSON SW, NORTH RA: Opioids excite dopamine neurons by hyperpolarization of local interneurons. $J$ Neurosci 12: 483-488, 1992.

KOOB GF: Drugs of abuse: anatomy, pharmacology and function of reward pathways. Trends Pharmacol Sci 13: 177-184, 1992.

KRAUS MF, BURCH EA JR: Methylphenidate hydrochloride as an antidepressant: controversy, case studies, and review. South Med J 85: 985-991, 1992.

LEONARD BE, MCCARTAN D, WHITE J, KING DJ: Methylphenidate: a review of its neuropharmacological, neuropsychological and adverse clinical effects. Hum Psychopharmacol 19: 151-180, 2004.

LIN Y, MORROW TJ, KIRITSY-ROY JA, TERRY LC, CASEY KL: Cocaine: evidence for supraspinal, dopaminemediated, non-opiate analgesia. Brain Res 479: 306-312, 1989.

LOWER EE, FLEISHMAN S, COOPER A, ZELDIS J, FALECK H, YU Z, MANNING D: Efficacy of dexmethylphenidate for the treatment of fatigue after cancer chemotherapy: a randomized clinical trial. J Pain Symptom Manage 38: 650-662, 2009.

MORADI M, YAZDANIAN M, HAGHPARAST A: Role of dopamine D2-like receptors within the ventral tegmental area and nucleus accumbens in antinociception induced by lateral hypothalamus stimulation. Behav Brain Res 292: 508-514, 2015.

MORGAN MJ, FRANKLIN KBJ: 6-hydroxydopamine lesions of the ventral tegmentum abolish D-amphetamine and morphine analgesia in formalin test but not in the tail flick test. Brain Res 519: 144-149, 1990.

NG CG, BOKS MP, ROES KC, ZAINAL NZ, SULAIMAN AH, TAN SB, DE WIT NJ: Rapid response to methylphenidate as an add-on therapy to mirtazapine in the treatment of major depressive disorder in terminally ill cancer patients: a four-week, randomized, double-blinded, placebo-controlled study. Eur Neuropsychopharmacol 24: 491-498, 2014.

ROZANS M, DREISBACH A, LERTORA JJ, KAHN MJ: Palliative uses of methylphenidate in patients with cancer: a review. J Clin Oncol 20: 335-339, 2002.

SCHIFIRNET E, BOWEN SE, BORSZCZ GS: Separating analgesia from reward within the ventral tegmental area. Neuroscience 263: 72-87, 2014.

SCHREIBER S, BADER M, RUBOVITCH V, PICK CG: Interaction between methylphenidate, methadone and different antidepressant drugs on antinociception in mice, and possible clinical implications. World J Biol Psychiatry 3: 1-8, 2015. 
SNITSELAAR MA, SMITS MG, VAN DER HEIJDEN KB, SMIT A, SPIJKER J: Influence of methylphenidate on circadian rhythmicity and sleep in adult attention-deficit/hyperactivity disorder. Sleep Biol Rhythms 11: 282-285, 2013.

SPRAGUE GL, TAKERMORI AE: Enhancement of morphine analgesia and brain levels by methamphetamine in mice. J Pharmacol Exp Ther 207: 485-493, 1978.

TANG B, DAFNY N: Methylphenidate modulates the locus coeruleus neuronal activity in freely behaving rat. Eur $J$ Pharmacol 695: 48-56, 2012.

TANG B, DAFNY N: Dorsal raphe neuronal activities are modulated by methylphenidate. J Neural Transm (Vienna) 120: 721-731, 2013.

TAYLOR AM, BECKER S, SCHWEINHARDT P, CAHILL C: Mesolimbic dopamine signaling in acute and chronic pain: implications for motivation, analgesia, and addiction. Pain 157: 1194-1198, 2016.

TREISTER R, EISENBERG E, DEMETER N, PUD D: Alterations in pain response are partially reversed by methylphenidate (Ritalin) in adults with attention deficit hyperactivity disorder (ADHD). Pain Pract 15: 4-11, 2015.

TRENQUE T, HERLEM E, ABOU TAAM M, DRAME M: Methylphenidate off-label use and safety. Springerplus 3: 286, 2014.

VOLKOW ND, SWANSON JM: Variables that affect the clinical use and abuse of methylphenidate in the treatment of ADHD. Am J Psychiatry 160: 1909-1918, 2003.

VOLKOW ND, FOWLER JS, WANG GJ, DING YS, GATLEY SJ: Role of dopamine in the therapeutic and reinforcing effects of methylphenidate in humans: results from imaging studies. Eur Neuropsychopharmacol 12: 557-566, 2002.

WILENS TE, BIEDERMAN J: The stimulants. Psychiatr Clin North Am 15: 191-222, 1992.

YAMAMOTOVÁ A, ŠLAMBEROVÁ R: Behavioral and antinociceptive effects of different psychostimulant drugs in prenatally methamphetamine-exposed rats. Physiol Res 61 (Suppl 2): S139-S147, 2012. 